\title{
Harnessing scientific developments in practice
}

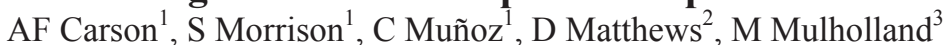

${ }^{1}$ Agri-Food and Biosciences Institute, Agriculture Branch, Hillsborough, Co. Down, United Kingdom, ${ }^{2}$ Agri-Food and Biosciences Institute, Agriculture Branch, Belfast, Co. Antrim, United Kingdom, ${ }^{3}$ College of Agriculture, Food and Rural Enterprise, Co. Antrim, United Kingdom

Email: camila.munoz@afbini.gov.uk

Introduction Adoption of innovations, be they new policies, technologies or products, is fundamental to the sustainable development of the agri-food industry in the UK and Ireland. This paper will review factors influencing the adoption of new scientific developments and, in this context, evaluate the linkages between research and the rural community in Northern Ireland. Information will be drawn from a range of sources, including a recent study of technology transfer on dairy farms (Morrison et al., 2009).

Farmer decision-making Much work has gone into understanding and modelling farmer decision-making (e.g. Garforth et al., 2004; Edwards-Jones, 2006). This has identified a large number of financial and non-financial factors associated with the level, and rate, of uptake of new innovations. The most important issues dairy producers in Northern Ireland considered when deciding on the adoption of research findings were, 'what are the financial rewards of the change?', followed by 'what is the cost of adopting the change?' and 'what is the labour/time/energy required to change?' (Morrison et al., 2009).

Non-financial variables associated with the uptake of technology include: farmer characteristics (age, level of education, gender); household characteristics (stage in family cycle, level of pluriactivity, work patterns of spouse); farm business structure (farm type and size, fragmentation, land quality and debt to asset ratio); the wider social milieu (level of technology transfer activities, information flows, local culture, social capital, attitude of friends, the policy environment); characteristic of the innovation to be adopted (visibility, compatibility, similarity with existing technology) and the farmer's psychological make-up (farmer attitudes and beliefs). For example, technology adoption happens quicker when the individual is younger or less experienced, better educated, receptive to new ideas, self confident and in a position to access economic resources and make decisions; the farm system is large, profitable and linked to other businesses and knowledge networks; the innovation system is linked, or in contact with, farmers and more involved in managementintensive technology than in capital-intensive technology (Massey, 2004). Understanding these factors, and their interactions, is crucial in developing appropriate technology transfer programmes.

Technology transfer models Technology transfer models can be grouped largely into one of five major strategies or communication methods: (i) linear 'top-down' transfer of technology from scientific experts to farmers, (ii) participatory 'bottom-up' and group based approaches, (iii) one-to-one advice or information exchange (whether from farmer to farmer or from professional adviser to farmer and vice versa), (iv) formal or structured education and training and (v) new information technologies (particularly internet). It is recognised that no single model or strategy is likely to be sufficient by itself (Black, 2000) and in Northern Ireland a number of approached are taken. In the area of sustainable livestock systems, large scale applied research programmes are undertaken on commercial farms across the region linked to more basic research programmes carried out within the Agri-Food and Biosciences Institute (AFBI). This type of model embeds technology transfer into research programmes and ensures the 2-way flow of information between the industry and research right from the outset of the work. Funding from farmers through AgriSearch (producer levy), along with the Department of Agriculture and Rural Development (DARD), has played a crucial role in the development of this work. Focus Farms have been established in Northern Ireland to promote good practice by example and monitor farms selected to provide a focus for farmer-driven discussion groups. DARD provides a business development service for farmers and growers providing one-to-one advice and has responsibilities in relation to education and training courses for the land-based and food industries and development programmes. Good linkages between research and education are crucial in establishing strong connections with new entrants to the industry and helping ensure new scientific developments are rolled out in a timely manner.

Creating the right environment for adoption and change To be effective, technology transfer programmes need to create the right environment for change to occur. Devenish (2006) reported the key factors are: (1) extensive knowledge of the problem, (2) working with farmers to identify and overcome barriers to adoption (3) involvement of a credible researcher, specialist or extension practitioner (4) experience in various communication methods and (5) funding to support research and development activities. Success might still be achieved if one key factor or process is missing, but if 2 or 3 factors are ignored or missing the programme is likely to fail as an effective means of promoting adoption and change.

Conclusions The effective adoption of scientific developments is a key determinant of the economic return achieved from investments in research, as well as being fundamental to the sustainable development of the agri-food sector. Central to its success is the inclusion of researchers at all stages of the process to help overcome barriers to adoption.

\section{References}

Black, A.W. 2000. Extension theory and practice: a review. Australian Journal of Experimental Agriculture 40, 493-502

Devenish, K. 2006. Proceedings of APEN International Conference, 6-8 March, Beechworth, Victoria, Australia

Edwards-Jones, G. 2006. Animal Science 82, 783-790.

Garforth, C., Rehman, T., Mckemey, K., Tranter, R., Cooke R., Yates, C., Park, J. and Dorward, P. 2004. Journal of Farm Management 12, 17-32.

Massey, C., Morriss, S., Flett, R. and Alpass, F. 2004. Journal of Extension 42(3), online.

Morrison, S.J., Carson, A.F., Mulholland, M. and Matthews, D. 2009. Proceedings of the Agriculture Forum 2009, 69A 